\title{
A new method for estimating UV fluxes at ground level in cloud-free conditions
}

\author{
William Wandji Nyamsi ${ }^{1,2}$, Mikko R. A. Pitkänen ${ }^{2,3}$, Youva Aoun ${ }^{1}$, Philippe Blanc ${ }^{1}$, Anu Heikkilä ${ }^{4}$, Kaisa Lakkala ${ }^{4,5}$, \\ Germar Bernhard $^{6}$, Tapani Koskela ${ }^{7}$, Anders V. Lindfors ${ }^{2}$, Antti Arola ${ }^{2}$, and Lucien Wald ${ }^{1}$ \\ ${ }^{1}$ Mines ParisTech, PSL Research University, Centre Observation, Impacts, Energy, Sophia Antipolis, France \\ ${ }^{2}$ Finnish Meteorological Institute, Kuopio, Finland \\ ${ }^{3}$ Department of Applied Physics, University of Eastern Finland, Kuopio, Finland \\ ${ }^{4}$ Finnish Meteorological Institute, Climate Research, Helsinki, Finland \\ ${ }^{5}$ Finnish Meteorological Institute, Arctic Research, Sodankylä, Finland \\ ${ }^{6}$ Biospherical Instruments Inc., San Diego, California, USA \\ ${ }^{7}$ Independent researcher, Helsinki, Finland
}

Correspondence: William Wandji Nyamsi (william.wandji@fmi.fi)

Received: 1 July 2017 - Discussion started: 10 August 2017

Revised: 3 November 2017 - Accepted: 6 November 2017 - Published: 19 December 2017

\begin{abstract}
A new method has been developed to estimate the global and direct solar irradiance in the UV-A and UV-B at ground level in cloud-free conditions. It is based on a resampling technique applied to the results of the $k$ distribution method and the correlated- $k$ approximation of Kato et al. (1999) over the UV band. Its inputs are the aerosol properties and total column ozone that are produced by the Copernicus Atmosphere Monitoring Service (CAMS). The estimates from this new method have been compared to instantaneous measurements of global UV irradiances made in cloud-free conditions at five stations at high latitudes in various climates. For the UV-A irradiance, the bias ranges between $-0.8 \mathrm{~W} \mathrm{~m}^{-2}(-3 \%$ of the mean of all data) and $-0.2 \mathrm{~W} \mathrm{~m}^{-2}(-1 \%)$. The root mean square error (RMSE) ranges from $1.1 \mathrm{~W} \mathrm{~m}^{-2}(6 \%)$ to $1.9 \mathrm{~W} \mathrm{~m}^{-2}(9 \%)$. The coefficient of determination $R^{2}$ is greater than 0.98 . The bias for UV-B is between $-0.04 \mathrm{~W} \mathrm{~m}^{-2}(-4 \%)$ and $0.08 \mathrm{~W} \mathrm{~m}^{-2}$ $(+13 \%)$ and the RMSE is $0.1 \mathrm{~W} \mathrm{~m}^{-2}$ (between 12 and $18 \%) . R^{2}$ ranges between 0.97 and 0.99 . This work demonstrates the quality of the proposed method combined with the CAMS products. Improvements, especially in the modeling of the reflectivity of the Earth's surface in the UV region, are necessary prior to its inclusion into an operational tool.
\end{abstract}

\section{Introduction}

Solar ultraviolet (UV) radiation at the Earth's surface has beneficial and adverse effects on human health (Juzeniene et al., 2011). For instance, UV radiation is a principal source of vitamin D, while the excess UV exposure is a risk factor for skin cancers, cataracts and immunosuppression. The wavelength dependence of these effects is typically characterized by action spectra. The most widely used one is the standardized action spectrum for erythema, which is also known as the CIE (Commission Internationale de l'Eclairage) spectrum (McKinlay and Diffey, 1987). There are also other action spectra related to skin cancer and melanoma (de Gruijl et al., 1993; Setlow et al., 1993). Emphasis has been placed mostly on the assessment of the solar UV erythemal irradiance and the derived quantity, the UV index, which is a very popular quantity to inform the public about UV levels. The UV index is also used in campaigns promoting safe Sun exposure. While the UV-B $[280,320] \mathrm{nm}$ band is the major contributor to erythemal $\mathrm{UV}$, interest is growing in the role of UV-A [320, 400] $\mathrm{nm}$ and UV [280, 400] nm on various diseases, such as viral infections (Norval, 2006), multiple sclerosis (Orton et al., 2011), Parkinson's disease (Kravietz et al., 2017), eye diseases (Delcourt et al., 2014), skin cancer (Coste et al., 2015; Fortes et al., 2016) or thyroid cancer (Mesrine et al., 2017), among many others (Juzeniene et al., 2011; Norval and Halliday, 2011). 
Ground-based spectroradiometers are one of the means to monitor the intensity of solar UV fluxes. Such measurements are rare due to the high costs of the instruments, operations and maintenance. To overcome this scarcity, many researchers have looked for proxies and have studied the relationship between UV radiation and the surface downwelling solar radiation integrated from 280 to $2800 \mathrm{~nm}$, called broadband radiation, since the latter is measured at a greater number of stations or can be estimated at any place from satellite images (Blanc et al., 2011; Lefèvre et al., 2014). Several empirical relationships have been published that relate, with the knowledge of the total ozone column (TOC), the broadband irradiance to the erythemal UV (den Outer et al., 2010; Calbó et al., 2005) or the UV-A, UV-B or UV irradiance (Aculinin et al., 2016; Canada et al., 2003; Foyo-Moreno et al., 1998).

An alternative way is the use of an appropriate radiative transfer model (RTM) together with accurate inputs describing the state of the atmosphere in cloud-free conditions and the properties of the ground surrounding the instrument, such as libRadtran (Emde et al., 2016; Mayer and Kylling, 2005). A comparison between 1200 measured UV spectra and estimates made with a previous version called uvspec - now part of libRadtran - with only ozone and aerosol optical properties as inputs yielded very good performance for simulating the UV irradiance under cloud-free conditions (Mayer et al., 1997). The relative biases ranged between -11 and $+2 \%$ for wavelengths between 295 and $400 \mathrm{~nm}$ and solar zenithal angles (SZA) up to $80^{\circ}$. Using measurements from sites in Finland, Norway and Sweden, Lindfors et al. (2007, 2009) showed that erythemal UV and spectral UV irradiances can be accurately modeled using libRadtran and broadband radiation, TOC, the total water vapor column from the ERA-40 data set, the surface albedo as estimated from snow depth and the altitude of the location as input.

RTMs are usually computationally expensive; hundreds of spectral calculations are required to compute the UV irradiance in an RTM. Strategies have been built to reduce the amount of calculations. Among them are the $k$ distribution method and correlated- $k$ approximation by Kato et al. (1999). The approach was originally designed for the calculation of the broadband solar irradiance. It consists in calculating the total solar irradiance, i.e., integrated between 240 and $4000 \mathrm{~nm}$, with only 32 spectral calculations in the spectral range between 240 and $4606 \mathrm{~nm}$. The operational McClear model estimating the total irradiance in cloud-free conditions accurately reproduces the irradiance computed by libRadtran based on the Kato et al. (1999) approach (Lefèvre et al., 2013). The McClear model uses several look up tables computed by libRadtran for selected values of inputs and provides the irradiance at each of the 32 spectral intervals. Hereafter, these 32 spectral intervals are named Kato bands and abbreviated $\mathrm{KB}$ with the number in subscript. Four KBs cover the whole $\mathrm{UV}$ range: $\mathrm{KB}_{3}[283,307] \mathrm{nm}, \mathrm{KB}_{4}[307$, $328] \mathrm{nm}, \mathrm{KB}_{5}[328,363] \mathrm{nm}$ and $\mathrm{KB}_{6}[363,408] \mathrm{nm}$. In $\mathrm{KB}_{1}$ and $\mathrm{KB}_{2}$, atmospheric ozone attenuates the radiation before it reaches the ground.

Wandji Nyamsi et al. (2014) compared atmospheric transmissivities obtained by the Kato et al. (1999) approach against those obtained by spectrally resolved computations using two RTMs in each of the $32 \mathrm{KBs}$. These calculations were performed for a set of 200000 realistic atmospheres and clouds. As for the UV band, the authors found that the Kato et al. (1999) approach offers very accurate estimates of irradiances in $\mathrm{KB}_{5}$ and $\mathrm{KB}_{6}$. On the contrary, a very large underestimation of the transmissivity was observed in $\mathrm{KB}_{3}[283,307] \mathrm{nm}$ and $\mathrm{KB}_{4}[307,328] \mathrm{nm}$ by respectively -93 and $-16 \%$ in relative value and exhibits a relative root mean square error (RMSE) of 123 and $17 \%$ in clear-sky conditions. Similar relative errors are observed for cloudy conditions. This is due to the assumption made by Kato et al. (1999) that in these bands a single ozone cross section at the central wavelength is sufficient to accurately represent the absorption by ozone over the whole interval. In a subsequent work, Wandji Nyamsi et al. (2015b) have proposed a novel parameterization using more than one single ozone cross sections which accurately represents the transmissivity due to ozone absorption. The novel parameterization of the transmissivity using more quadrature points yields maximum errors of respectively 0.0006 and 0.0143 for intervals $\mathrm{KB}_{3}$ and $\mathrm{KB}_{4}$. Version 2.0.1 of libRadtran (Emde et al., 2016) includes this correction and has been used in this study.

The KBs do not fit the UV spectral ranges exactly and a spectral resampling is necessary. This is the subject of the present article. The concept of the novel method is to determine several $1 \mathrm{~nm}$ spectral bands whose atmospheric transmissivities are correlated to those of the $\mathrm{KB}$ and are then used in a linear interpolation process to compute the UV irradiance. The method is empirically implemented by the means of libRadtran in cloud-free conditions. The concept has already been tested for photosynthetically active radiation simulated by libRadtran (Wandji Nyamsi et al., 2015a). Now, the concept is tested for actual UV fluxes. This work is part of a larger project whose overarching goal is to create an operational tool for estimating UV fluxes. In particular, it exploits the recent results on aerosol properties and TOC produced by the Copernicus Atmosphere Monitoring Service (CAMS) for any location and any time after 2003. The performance of the novel method is assessed by a comparison against high-quality measurements of UV fluxes performed in cloud-free conditions. Stations have been selected to fulfill two main constraints. The first one is that the measurement has to be carried out during a cloud-free instant, meaning that it either should be clearly marked or should use an algorithm for selecting cloud-free instants, which most of the time requires broadband measurements as inputs. The second one is that high-quality control and assurance should be applied to the measurement. Following these constraints, five stations which are located at high latitudes were selected. 


\section{Description of measurements used for comparison}

Ground-based measurements were collected from three sites of the UV network of the National Science Foundation (NSF) of the USA and two sites of the Finnish Meteorological Institute (FMI). Table 1 reports the geographical coordinates of the stations, time period of data and their source, type of instruments, spectral interval and step of measurements.

The Barrow site is located approximately $6 \mathrm{~km}$ northeast of the Barrow city in Alaska, on the coast of the Chukchi Sea, part of the Arctic Ocean, usually covered by ice between November and July. The snow cover of the surroundings of the station extends from October until June. According to Bernhard et al. (2008), the effective UV albedo of the surface reaches its maximum of approximately 0.8 during March-April. It decreases to 0.05 in summer from August until September.

The Sodankylä site is approximately $6 \mathrm{~km}$ south of the village of Sodankylä. The site is located in the vicinity of the river Kitinen, and the surroundings are boreal pine forest and large peatland areas. A permanent snow cover is present during the winter and the annual number of snowy days is on average 190. The snow cover starts accumulating in October or November and melts away during May almost every year. The effective UV albedo follows a seasonal variation due to the snow cover. It ranges from very low values in boreal summer up to 0.65 in winter (Arola et al., 2003).

Jokioinen Observatory is located in a fairly flat rural area in the southwest of Finland surrounded by fields of agriculture and a boreal forest. The number of snowy days is typically 130. The snow conditions in Jokioinen vary from year to year and also within each winter. At the earliest, snow may appear at the end of October or early November, while it typically melts away in March or April. The effective UV albedo is highly variable; it may rise up to 0.58 in boreal winter but more typical values are 0.2 to 0.5 (Lindfors et al., 2007).

Palmer is situated on Anvers Island, which is on the western side of the Antarctic Peninsula. The ocean surrounding the island is frozen during austral winter and usually ice-free in summer. According to Bernhard et al. (2005), the effective UV albedo varies between 0.6 and 0.95 occurring from August until November and then decreases down to 0.3 to 0.5 after snowmelt. It is large even in austral summer because of the glaciers surrounding the site.

McMurdo is a coastal site located on Ross Island, a volcanic island of Antarctica surrounded by a persistence of the ice sheet. The surroundings of the station are mostly made of dark volcanic rocks. McMurdo has an annual cycle of change in effective UV albedo. It ranges between 0.54 (March) and 0.99 (October) (Bernhard et al., 2006).

WMO (2008) reports that uncertainties associated with the measurements in UV by spectrometers are difficult to estimate precisely. Beyond the technical specifics of the site itself, several errors may occur in the calibration of the instrument that include (i) the uncertainties associated with irradiance transfer standards, (ii) the stability of instruments over time and (iii) imperfect directional response. The WMO guide estimates that a $5 \%$ measurement uncertainty at $300 \mathrm{~nm}$ can be achieved only under the most rigorous conditions at the present time.

The data provided by the NSF are available online and can be downloaded freely. Only data of version 2, which have been corrected for the instruments' cosine error, have been selected to ensure higher accuracy. Data measured during clear-sky conditions are flagged (flag "CS"). The number of clear-sky instants is reported in Table 1. Integrated irradiances in the UV-A and UV-B range are available and have been downloaded from the website http://uv.biospherical. com/Version2.

The data for the two Finnish sites have been corrected for all known errors following the routine spectral UV data processing procedure of the FMI (Lakkala et al., 2008; Mäkelä et al., 2016). The irradiance scale of the FMI's Brewer spectrophotometers is traceable to that maintained by the Finnish National Standards Laboratory at VTT MIKES Metrology and maintained by a rigorous schedule for measurements of primary standard, secondary standard and working standard lamps (Heikkilä et al., 2016a). In this work, the measured UV spectra were first deconvoluted and then convoluted with a standard triangular slit function with a full width at half maximum of $1 \mathrm{~nm}$ and extrapolated using the SHICrivm software package (http://www.rivm.nl/en/Topics/U/UV_ozone_layer_ and_climate/SHICrivm) (Slaper and Koskela, 1997; Slaper et al., 1995) to cover the full UV spectrum as explained in Heikkilä et al. (2016b). Spectral irradiances are integrated over the UV-B and UV-A. The uncertainties related to the extrapolation are less than 2 and $3 \%$ in the integrated UVA, for the Jokioinen and Sodankylä Brewers respectively when averaged over daily time window. However, for individual spectra the uncertainties are estimated to be somewhat higher, up to 5-6\% for Sodankylä Brewer with the highest measured wavelength at $325 \mathrm{~nm}$ (H. Slaper, personal communication, 2017).

In addition, at both Finnish stations, direct, diffuse and global broadband irradiances are measured every $1 \mathrm{~min}$, with the global irradiance being the sum of the direct and diffuse irradiances on a horizontal plane. These series of data are exploited for selecting cloud-free instants by using the very restrictive algorithm proposed by Lefèvre et al. (2013). The latter is made of two successive filters. The first one is a constraint on the amount of diffuse irradiance with respect to the global irradiance since the direct irradiance is usually prominent in cloud-free conditions. The second filter analyzes the temporal variability in the global irradiance normalized by the irradiance received at the top of the atmosphere and by a typical air mass since this quantity should be steady for several hours in cloud-free conditions. We assume that a cloudfree instant detected by analyzing broadband irradiances is also cloud-free for the spectral measurements. It is possible that UV is affected by the presence of scattered cloudiness, 
Table 1. Description of stations used for validation, ordered by decreasing latitude.

\begin{tabular}{|c|c|c|c|c|c|}
\hline Station & Barrow & Sodankylä & Jokioinen & Palmer & McMurdo \\
\hline Source & NSF & FMI & FMI & NSF & NSF \\
\hline Latitude $\left({ }^{\circ}\right)$ & 71.32 & 67.37 & 60.82 & -64.77 & -77.83 \\
\hline Longitude $\left({ }^{\circ}\right)$ & -156.68 & 26.63 & 23.50 & -64.05 & 166.67 \\
\hline Altitude (m) & 8 & 179 & 104 & 21 & 183 \\
\hline Instrument & $\begin{array}{l}\text { SUV-100 spectro- } \\
\text { radiometer }\end{array}$ & $\begin{array}{l}\text { Brewer spectro- } \\
\text { radiometer } \\
\text { MK-II no. } 037\end{array}$ & $\begin{array}{l}\text { Brewer spectro- } \\
\text { radiometer } \\
\text { MK-III no. } 107\end{array}$ & $\begin{array}{l}\text { SUV-100 spectro- } \\
\text { radiometer }\end{array}$ & $\begin{array}{l}\text { SUV-100 spectro- } \\
\text { radiometer }\end{array}$ \\
\hline Average acquisition frequency & 4 spectra per hour & $\begin{array}{l}\text { between } 1 \text { and } 2 \\
\text { spectra per hour }\end{array}$ & $\begin{array}{l}\text { between } 1 \text { and } 2 \\
\text { spectra per hour }\end{array}$ & 4 spectra per hour & 4 spectra per hour \\
\hline Spectral range $(\mathrm{nm})$ & $280-600$ & $290-325$ & $286.5-365$ & $280-600$ & $280-600$ \\
\hline Step $(\mathrm{nm})$ & $\begin{array}{l}0.2 \text { in UV-B to } 1.0 \\
\text { in visible }\end{array}$ & 0.5 & 0.5 & $\begin{array}{l}0.2 \text { in UV-B to } 1.0 \\
\text { in visible }\end{array}$ & $\begin{array}{l}0.2 \text { in UV-B to } 1.0 \\
\text { in visible }\end{array}$ \\
\hline Period & $2005-01$ to $2010-11$ & $2007-01$ to $2011-12$ & $2007-01$ to $2008-12$ & $2005-01$ to $2010-09$ & $2005-01$ to $2010-02$ \\
\hline NCFI* & 4293 & 2590 & 1140 & 1736 & 10175 \\
\hline
\end{tabular}

* NCFI: number of cloud-free instants.

which may go unnoticed in the broadband range, and that the retained series of cloud-free instants for broadband may comprise cloudy instants for UV. Given the high selectivity of the algorithm of Lefèvre et al. (2013), we believe that such cases are rare and that the conclusions will be unaffected as a whole.

\section{Description of the new method}

In brief, the method combines the fluxes estimated by libRadtran in the four KBs and performs a resampling of these fluxes for retrieving UV fluxes. For all the radiative transfer simulations, a plane-parallel atmosphere was assumed and the DISORT 2.0 (discrete ordinate technique) algorithm (Stamnes et al., 2000) with 16 streams was selected to solve the radiative transfer equation because several articles have demonstrated the accuracy of its results when compared to robust and more time-consuming solvers.

\subsection{Inputs to libRadtran}

In cloud-free conditions, UV irradiance at ground level depends mostly on the SZA $\left(\theta_{\mathrm{S}}\right)$; the ground albedo; the total column content of ozone; the vertical profile of ozone, temperature, pressure, density and volume mixing ratio for gases as a function of altitude; aerosol optical depth (AOD); the Ångström coefficient; and aerosol type and the elevation of the ground above sea level. As the method shall be used operationally, the sources of these inputs have been selected to allow estimation of UV irradiance at any location and any time.

The Copernicus Atmosphere Monitoring Service of the European Commission provides aerosol properties together with physically consistent TOC for any place and any time after 2003. Along with TOC, the AOD at $550 \mathrm{~nm}$, Ångström coefficient and aerosol type are collected from this source of data following exactly the path of the McClear model
(Lefèvre et al., 2013). $\theta_{\mathrm{s}}$ is given by the SG2 algorithm for the Sun position and angles (Blanc and Wald, 2012). Ground elevation is extracted from the Shuttle Radar Topography Mission database and has been downloaded from the website http://srtm.csi.cgiar.org/SELECTION/inputCoord.asp.

The albedo is the ratio of the upwelling to downwelling flux at the surface and is the integral of the bidirectional reflectance distribution function (BRDF), which depends on the surface-type, its roughness and the wavelength of the impinging radiation. A few institutes provide BRDF products in the UV range or Lambertian equivalent reflectivity (e.g., Herman and Celarier, 1997) of the Earth's surface with a coarse resolution of 0.5 or $1^{\circ}$. In absence of the ideal solution - BRDF parameters in the UV range available worldwide with a grid cell of $0.05^{\circ}$ or better - an approximate solution has been adopted by using the so-called shortwave $[250,5000] \mathrm{nm}$ BRDF parameters proposed by Blanc et al. (2014). The US National Aeronautics and Space Administration (NASA) provides worldwide maps of the BRDF parameters that are derived from the MODIS (Moderate Resolution Imaging Spectroradiometer) instrument (Schaaf et al., 2002). Blanc et al. (2014) have created a series of maps of the MODIS BRDF parameters for each calendar month for the shortwave albedo with no missing values at a spatial resolution of $0.05^{\circ}$. In addition, these authors proposed a method for computing the albedo simultaneously for direct and global irradiances. These maps and this method are those used by the McClear model (Lefèvre et al., 2013). As a first approximation, the UV albedo is assumed to be spectrally constant and equal to the shortwave albedo. This assumption may result in biases depending on the surface. For example, in the case of snow surface, Varotsos et al. (2014) reported from many aircraft measurements that spectral albedo exhibits a tendency to decrease with increasing wavelength of about 0.7 in UV to about 0.4 in the near-infrared independently of the sky conditions. Therefore, the albedo integrated over the spectrum becomes less than 0.7 , resulting in the un- 
derestimation in UV albedo, hence in a lesser contribution to diffuse UV irradiance, and therefore in the underestimation of the global UV.

\subsection{Resampling technique}

Let $\lambda$ be the wavelength, $G_{\lambda}$ the global spectral irradiance at the surface and $B_{\lambda}$ the direct normal spectral irradiance, i.e., the irradiance received from the direction of the Sun at the surface on a plane normal to the Sun's rays. The irradiance in a given interval $\left[\lambda_{1}, \lambda_{2}\right]$ is given by

$G_{\lambda 1 \lambda 2}=\int_{\lambda 1}^{\lambda 2} G_{\lambda} \mathrm{d} \lambda$.

Similar expressions may be obtained for irradiances in UVA, UV-B, UV or over $\mathrm{KB}_{j}$. For example, the UV irradiance $G_{\mathrm{UV}}$ and the direct normal irradiance $B_{\mathrm{UV}}$ or the irradiance $G_{\mathrm{KB} 4}$ in $\mathrm{KB}_{4}$ are given by

$$
\begin{aligned}
G_{\mathrm{UV}} & =\int_{280}^{400} G_{\lambda} \mathrm{d} \lambda, \\
B_{\mathrm{UV}} & =\int_{280}^{400} B_{\lambda} \mathrm{d} \lambda, \\
G_{\mathrm{KB} 4} & =\int_{307}^{328} G_{\lambda} \mathrm{d} \lambda,
\end{aligned}
$$

where $\lambda$ is expressed in $\mathrm{nm}$.

The KBs do not fit the UV spectral ranges exactly. For example, the UV-B is covered by $\mathrm{KB}_{3}$ and a part of $\mathrm{KB}_{4}$. One solution to estimate the irradiance in a UV interval is the use of weighted sums based on the overlap between $\mathrm{KB}_{j}$ and this interval. Another technique is adopted here whose concept is to determine several $1 \mathrm{~nm}$ spectral bands $\mathrm{NB}_{i}$ whose transmissivities are correlated to those of the $\mathrm{KB}_{j}$ and are then used in a linear interpolation process to compute the UV irradiance. A similar approach has been used by Wandji Nyamsi et al. (2015a) for the calculation of the photosynthetically active radiation with better results than a weighted sum.

If one assumes that the optical properties of the atmosphere do not change over a given $\mathrm{NB}_{i}$, the integrals of Eqs. (2)-(4) may be replaced by Riemann sums over $\mathrm{NB}_{i}$. For example, if $\lambda_{i}$ denotes the central wavelength of $\mathrm{NB}_{i}$, $G_{\mathrm{UV}}$ can be approximated by

$G_{\mathrm{UV}}=\sum_{i=1}^{120} G_{\lambda i}$

If one defines the clearness index $\mathrm{KT}_{i}$ as

$\mathrm{KT}_{i}=\frac{G_{\lambda i}}{\mathrm{Eo}_{i} \cos \left(\Theta_{\mathrm{s}}\right)}$, where $\mathrm{Eo}_{i}$ is the irradiance at the top of atmosphere on a plane normal to the Sun's rays for $\mathrm{NB}_{i}$ for a given instant $t$, Eq. (5) becomes

$G_{\mathrm{UV}}=\cos \left(\Theta_{\mathrm{S}}\right) \sum_{i=1}^{120} \mathrm{Eo}_{i} \mathrm{KT}_{i}$

Similarly, the clearness index $\mathrm{KT}_{\mathrm{KB}_{j}}$ for $\mathrm{KB}_{j}$ is given by

$\mathrm{KT}_{\mathrm{KB}_{j}}=\frac{G_{\mathrm{KB}_{j}}}{\mathrm{Eo}_{\mathrm{KB}_{j}} \cos \left(\Theta_{\mathrm{s}}\right)}$.

The solar spectrum of Gueymard (2004) available in libRadtran was combined with the algorithm SG2 for computing the Sun position (Blanc and Wald, 2012) to yield $\mathrm{Eo}_{i}$ and $\mathrm{EoKB}_{j}$.

For the method presented here, we assume that simple and accurate relations, e.g., affine functions, may be found between each $\mathrm{KT}_{\mathrm{KB}}$ and a subset of several $\mathrm{KT}_{i}$, called $\mathrm{KT}_{k}$ hereafter. Then it may be possible to interpolate linearly between $\mathrm{KT}_{k}$ to obtain an estimate of $\mathrm{KT}_{i}$ for each $\lambda_{i}$. By summing the products of $\mathrm{Eo}_{i}$ and these interpolated $\mathrm{KT}_{i}$ 's over a given spectral interval, it is then possible to compute the corresponding irradiance. This is the principle of the resampling technique. The set of $\mathrm{NB}_{k}$ is selected at the beginning of the procedure and the same set is used for all processing. The number of $\mathrm{NB}_{k}$ should be as small as possible in order to decrease the amount of calculations but still large enough to allow a good accuracy.

The selection of $\mathrm{NB}_{k}$ is empirically determined by means of libRadtran. The current approach is empirical with no guarantee that the selected set of $\mathrm{NB}_{k}$ is the optimum. It could have been possible to use some mathematical optimization tools. This is not a straightforward process as the cost function should take into account that the number of $\mathrm{NB}_{k}$ is unknown a priori.

A set of 60000 clear-sky atmospheric states was built by means of the Monte Carlo technique in order to select $\mathrm{NB}_{k}$. Each state comprises the nine variables described above, and the value of each variable was randomly selected by taking into account their modeled marginal distribution. The distributions proposed by Lefèvre et al. (2013) and Oumbe et al. (2011) established from observations were adopted here (Table 2). More specially, the uniform distribution is chosen as a model for marginal probability for all variables except AOD, the Ångström exponent coefficient, and total column content of ozone. The chi-square law for AOD, the normal law for the Angström exponent coefficient, and the beta law for TOC have been selected. The selection of these parametric probability density functions and their corresponding parameters have been empirically determined from the analyses of the observations made in the Aerosol Robotic Network for aerosol properties and from meteorological satellite-based ozone products (Lefèvre et al., 2013).

Each atmospheric state is input twice to libRadtran, (1) with the Kato et al. (1999) approach yielding $\mathrm{KT}_{\mathrm{KB} 3}$, 
Table 2. Ranges and statistical distributions of values taken by the cosine of the solar zenith angle, the ground albedo and the 7 variables describing the clear atmosphere.

\begin{tabular}{|c|c|}
\hline Variable & Value \\
\hline Cosine of the SZA $\cos \left(\Theta_{\mathrm{S}}\right)$ & Uniform between 0 and 89 (degree) for $\Theta_{\mathrm{s}}$ \\
\hline Ground albedo $\rho g$ & Uniform between 0 and 0.9 \\
\hline Elevation of the ground above mean sea level & Equiprobable in the set $\{0,1,2,3\}(\mathrm{km})$ \\
\hline Total column content of ozone & $\begin{array}{l}\text { Ozone content is } 300 \times \beta+200 \text {, in Dobson unit. Beta distribution, with } A \text { pa- } \\
\text { rameter }=2 \text { and } B \text { parameter }=2 \text {, to compute } \beta\end{array}$ \\
\hline $\begin{array}{l}\text { Atmospheric profiles (Air Force Geophysics } \\
\text { Laboratory standards) }\end{array}$ & $\begin{array}{l}\text { Equiprobable in the set }\{\text { midlatitude summer, midlatitude winter, subarctic } \\
\text { summer, subarctic winter, tropical, US standard }\}\end{array}$ \\
\hline Aerosol optical depth at $550 \mathrm{~nm}$ & Gamma distribution, with shape parameter $=2$ and scale parameter $=0.13$ \\
\hline Ångström exponent coefficient & Normal distribution, with mean $=1.3$ and standard-deviation $=0.5$ \\
\hline Aerosol type & $\begin{array}{l}\text { Equiprobable in the set }\{\text { urban, rural, maritime, tropospheric, desert, continen- } \\
\text { tal, Antarctic }\}\end{array}$ \\
\hline
\end{tabular}

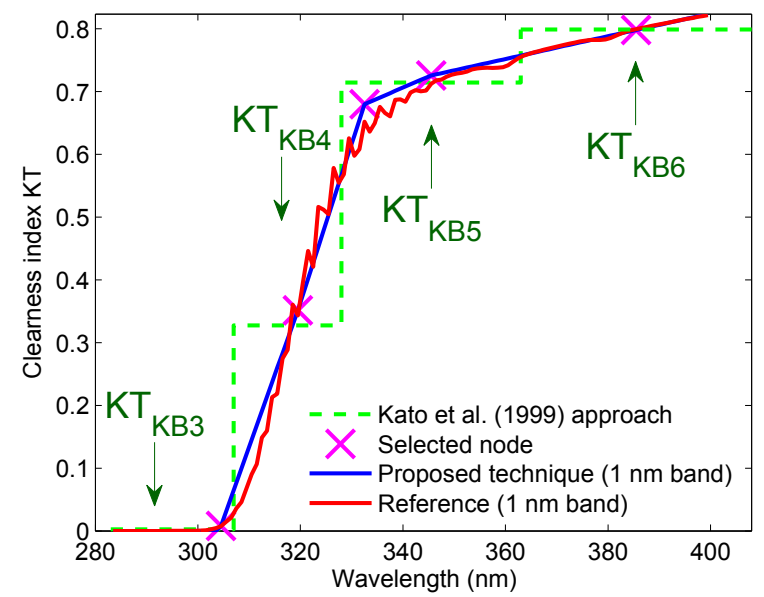

Figure 1. Illustration of the resampling technique.

$\mathrm{KT}_{\mathrm{KB} 4}, \mathrm{KT}_{\mathrm{KB} 5}$ and $\mathrm{KT}_{\mathrm{KB} 6}$ and (2) with detailed spectral computations providing $\mathrm{KT}_{i}$ every $1 \mathrm{~nm}$ for the interval [283, $408] \mathrm{nm}$. Several plots were made superimposing $\mathrm{KT}_{\mathrm{KB} 3}$, $\mathrm{KT}_{\mathrm{KB} 4}, \mathrm{KT}_{\mathrm{KB} 5}$ and $\mathrm{KT}_{\mathrm{KB} 6}$ (in green), and $\mathrm{KT}_{i}$ (in red). Figure 1 is such a graph with the following inputs: $\theta_{\mathrm{S}}$ of $53.76^{\circ}$, the midlatitude winter atmospheric profile, TOC of $470 \mathrm{DU}, \mathrm{AOD}$ of 0.78 at $1000 \mathrm{~nm}$ for a maritime polluted aerosol model with an Ångström exponent of 1.93, elevation of $0 \mathrm{~m}$ and surface albedo of 0.63 . A visual inspection shows that $\mathrm{KT}_{\mathrm{KB}_{j}}$ and $\mathrm{KT}_{i}$ are approximately equal for $\lambda_{j}$ in the middle of $\mathrm{KB}_{j}$, except for $\mathrm{KB}_{5} . \mathrm{KT}_{i}$ in this band exhibits a nonlinear behavior that cannot be accounted for with a single $\mathrm{KT}_{k}$. If one selects $305,320,333,346$ and $386 \mathrm{~nm}$ as $\mathrm{NB}_{k}$ (magenta crosses), then the linear interpolation (in blue) provides a fairly accurate estimate of $\mathrm{KT}_{i}$. The five $\mathrm{NB}_{k}$ 's were selected by a lengthy visual inspection of such plots and are reported in Table 3. The same $\mathrm{NB}_{k}$ 's apply for the global and direct irradiances. For each $\mathrm{NB}_{k}$, the parameters of the affine function relating $\mathrm{KT}_{\mathrm{KB}}$ and $\mathrm{KT}_{k}$ are determined by least- squares fitting technique (Table 3):

$\mathrm{KT}_{k}=a_{k} \mathrm{KT}_{\mathrm{KB}_{j}}+b_{k}$.

Another set of parameters is determined in the same way for the direct irradiance. In the operational mode, given an atmospheric state, a run of libRadtran, or a fast approximation of it, yields four $\mathrm{KT}_{\mathrm{KB}_{j}}$, from which the five $\mathrm{KT}_{k}$ 's are computed using the affine functions. Then, approximate $\mathrm{KT}_{i}^{*}$ 's are computed for each nm between 280 and $400 \mathrm{~nm}$ using a linear interpolation and extrapolation of $\mathrm{KT}_{k}$. In cases where extrapolation provides negative values, $\mathrm{KT}_{i}^{*}$ is set to 0 . Eventually, $G_{\mathrm{UV}}$ is obtained by

$G_{\mathrm{UV}}=\cos \left(\Theta_{\mathrm{s}}\right) \sum_{i=1}^{120} \mathrm{Eo}_{i} \mathrm{KT}_{i}^{*}$.

A similar process is performed for the direct normal irradiance $B_{\mathrm{UV}}$ as well as for the same quantities in UV-A and UV-B. As the method provides the spectrum $\mathrm{KT}_{i}^{*}$, the equation may be extended to include any action spectrum $S(\lambda)$, for example,

$G_{S(\lambda)}=\cos \left(\Theta_{\mathrm{s}}\right) \sum_{\lambda 1}^{\lambda 2} \mathrm{Eo}_{i} S(i) \mathrm{KT}_{i}^{*}$.

\subsection{Numerical validation}

In this section, results of the proposed technique are compared with results from the detailed spectral calculations made by libRadtran to assess the accuracy of the proposed technique for $G_{\mathrm{UVA}}, G_{\mathrm{UVB}}, B_{\mathrm{UVA}}$ and $B_{\mathrm{UVB}}$ for cloud-free conditions. The errors made by using the proposed technique for calculations of the UV-A and UV-B irradiances are presented. To that extent, an additional sample of 10000 atmospheric states has been randomly constructed following the marginal distribution variables described in Table 2 . The proposed technique was applied to the outputs of libRadtran using the Kato et al. (1999) approach and the estimates were 
Table 3. $\mathrm{KB}$ covering the UV band and selected subintervals $\mathrm{NB}_{k}$; slopes and intercepts of the affine functions between the clearness indices in $\mathrm{KB}$ and subintervals $\mathrm{NB}_{k}$.

\begin{tabular}{rrrrrrrr}
\hline \multirow{2}{*}{ KB } & KB range, & Subinterval NB $N_{k}$, & \multicolumn{2}{c}{ Global } & & \multicolumn{2}{c}{ Direct normal } \\
& $\mathrm{nm}$ & $\mathrm{nm}(\# k)$ & Slope $a_{i}$ & Intercept $b_{i}$ & & Slope $c_{i}$ & Intercept $d_{i}$ \\
\hline 3 & $283-307$ & $304-305(\# 1)$ & 3.0900 & 0.0007 & & 3.0852 & 0.0003 \\
4 & $307-328$ & $319-320(\# 2)$ & 1.1264 & -0.0175 & & 1.0886 & -0.0007 \\
5 & $328-363$ & $332-333(\# 3)$ & 1.0247 & -0.0519 & & 0.8992 & -0.0103 \\
& & $345-346(\# 4)$ & 0.9946 & 0.0152 & & 1.0112 & -0.0004 \\
6 & $363-408$ & $385-386(\# 5)$ & 1.0030 & -0.0032 & & 0.9987 & -0.0023 \\
\hline
\end{tabular}

Table 4. Statistical indicators of the performances of the proposed technique for estimating UV fluxes.

\begin{tabular}{lrrrrrr}
\hline $\begin{array}{l}\mathrm{UV} \\
\text { fluxes }\end{array}$ & $\begin{array}{r}\text { Mean } \\
\left(\mathrm{W} \mathrm{m}^{-2}\right)\end{array}$ & $\begin{array}{r}\text { Bias } \\
\left(\mathrm{W} \mathrm{m}^{-2}\right)\end{array}$ & $\begin{array}{r}\text { RMSE } \\
\left(\mathrm{W} \mathrm{m}^{-2}\right)\end{array}$ & $\begin{array}{r}\text { rBias } \\
(\%)\end{array}$ & $\begin{array}{r}\text { rRMSE } \\
(\%)\end{array}$ & $R^{2}$ \\
\hline$G_{\mathrm{UVA}}$ & 45.6 & +0.1 & 0.1 & +0.2 & 0.2 & 1.00 \\
$B_{\mathrm{UVA}}$ & 23.4 & -0.1 & 0.2 & -0.6 & 0.8 & 1.00 \\
$G_{\mathrm{UVB}}$ & 2.30 & -0.04 & 0.14 & -1.64 & 6.19 & 1.00 \\
$B_{\mathrm{UVB}}$ & 0.73 & +0.07 & 0.15 & +10.10 & 20.48 & 0.97 \\
\hline
\end{tabular}

compared to the detailed calculations performed by libRadtran. Following the ISO standard (1995), the deviations were computed by subtracting measurements for each instant from the results of the method. They were summarized by the bias (mean error), the root mean square error, and their values rBias and rRMSE relative to the mean value of the measurements. In addition, the coefficient of determination $\left(R^{2}\right)$ is computed.

Table 4 reports the statistical indicators for the global and direct normal UV-A and UV-B irradiances. For UV-A fluxes, the bias for the global irradiance and the direct irradiance is $+0.10 \mathrm{~W} \mathrm{~m}^{-2}$, i.e., $+0.2 \%$ in relative value, and $-0.15 \mathrm{~W} \mathrm{~m}^{-2}$, i.e., $-0.7 \%$ in relative value respectively. The RMSE is respectively $0.12 \mathrm{~W} \mathrm{~m}^{-2}(0.3 \%)$ and $0.18 \mathrm{~W} \mathrm{~m}^{-2}$ $(0.8 \%)$. For UV-B fluxes, the bias for the global irradiance and the direct irradiance is $-0.04 \mathrm{~W} \mathrm{~m}^{-2}$, i.e., $-1.6 \%$ in relative value, and $+0.07 \mathrm{~W} \mathrm{~m}^{-2}$, i.e., $+10.1 \%$ in relative value respectively. The corresponding RMSE is respectively $0.14 \mathrm{~W} \mathrm{~m}^{-2}(6.2 \%)$ and $0.15 \mathrm{~W} \mathrm{~m}^{-2}(20.5 \%)$. The coefficient of determination $R^{2}$ is greater than 0.99 except for the direct normal UV-B irradiance which is 0.966. Expectedly, these indicators prove the good level of performance of the proposed technique.

\section{Results}

The results of the proposed method were compared to measurements of UV-A and UV-B irradiances at the surface for cloud-free conditions. Similar statistical indicators as those presented in the previous section are also computed to synthetize the errors.

\subsection{Performance of the method for UV-A irradiance}

Figure 2 exhibits the scatter density plot between groundbased instantaneous measurements made for each station in cloud-free conditions and estimates from the proposed method combined with inputs from CAMS. The station name is indicated at the top of each plot. Figure 2a exhibits the results for Barrow. All points are well located along the identity line. The slope of the fitting line is 0.995 , i.e., very close to 1 , showing a very good estimation of the measurements by the method. $R^{2}$ is 0.97 , meaning that all the variability in the measurements is very well explained by the estimates. The bias is low with a value of $-0.2 \mathrm{~W} \mathrm{~m}^{-2}$, i.e., $-1 \%$ of the mean value of the measurements, $20.5 \mathrm{~W} \mathrm{~m}^{-2}$. The RMSE is small with a value of $1.4 \mathrm{~W} \mathrm{~m}^{-2}$, which is around $7 \%$ of the mean. These statistical indicators for each station are reported in Table 5. The measurements are mostly between March and September. The shortwave albedo is 0.8 from the beginning of March until the middle of May. With the progressive snowmelt, this shortwave albedo decreases from mid-May down to 0.12 in mid-July. This variation corresponds well to the climatological evolution reported by Bernhard et al. (2008) and supports the choice of this approximation by the shortwave albedo.

Even if the points follows the perfect line (Fig. 2a) quite well, a set of points is seen where the method noticeably underestimates by more than $20 \%$. These underestimations occurs between the end of May and mid-July. During that period, the shortwave albedo was less than the effective UV albedo by a factor 0.8 . The effective UV albedo is part of the version 2 dataset and was derived by comparing measured clear-sky spectra with corresponding radiative transfer model results (Bernhard et al., 2007). As a smaller albedo means a smaller contribution to the diffuse part of the irradiance, the difference between the shortwave and effective UV albedo may explain these underestimations seen in Fig. 2a.

Results for Sodankylä are shown in Fig. 2b. Cloud-free conditions occur mostly between February and September. The points lie along the identity line with a slight overestimation by the method at low irradiance and an underestimation at large irradiance. $R^{2}$ is 0.98 . The bias is low with a value of $-0.5 \mathrm{~W} \mathrm{~m}^{-2}$, i.e., $-2 \%$ of the mean value of $20.8 \mathrm{~W} \mathrm{~m}^{-2}$. 

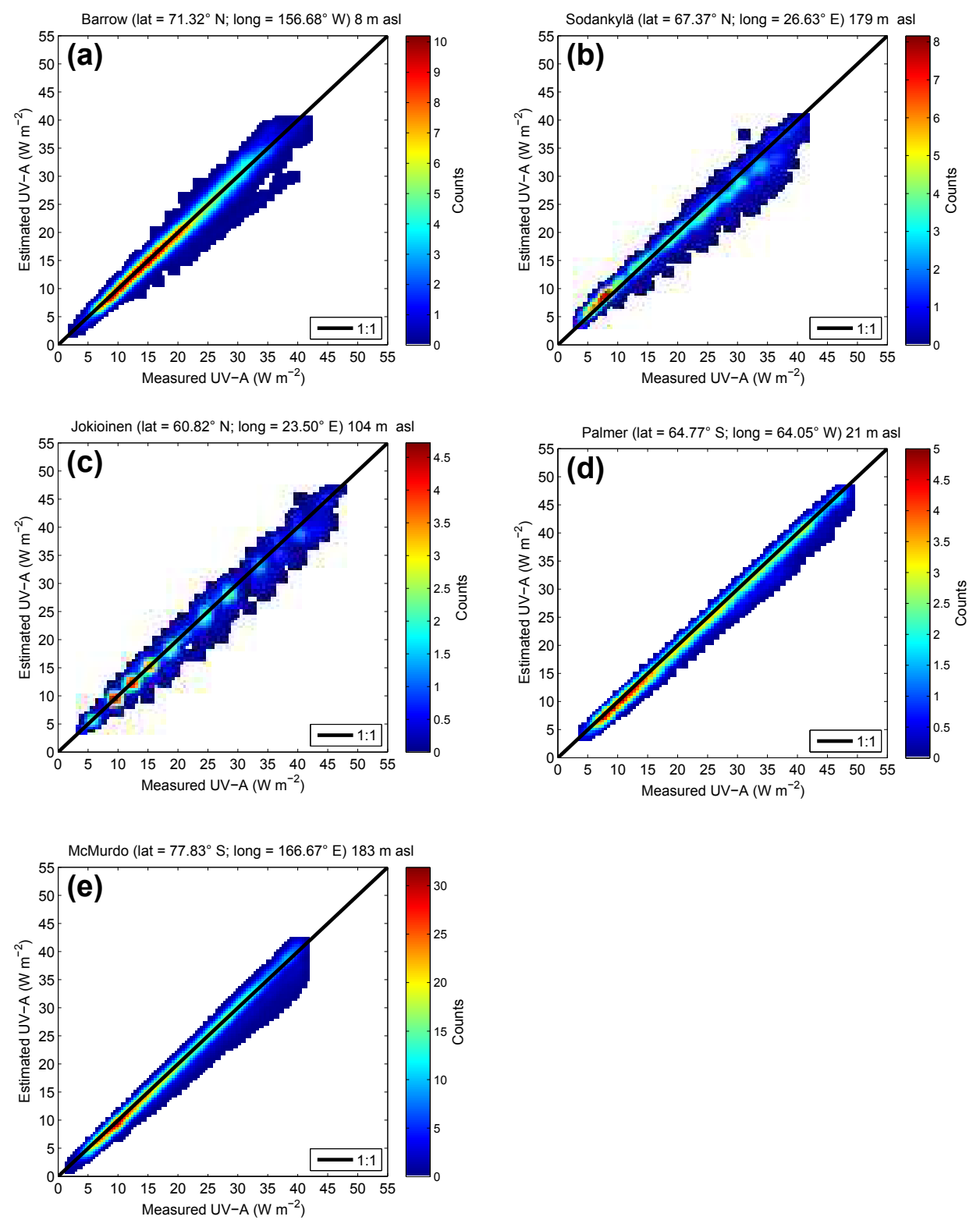

Figure 2. Scatter density plot between measurements of UV-A and estimates for each station with each station name at the top. The color bar indicates the number of points in the area within the interval $0.4 \mathrm{~W} \mathrm{~m}^{-2} \times 0.4 \mathrm{~W} \mathrm{~m}^{-2}$.

Table 5. Statistical indicators of the performances of the method for UV-A irradiance. $N$ is the number of data points.

\begin{tabular}{lrrrrrrr}
\hline Station & $N$ & $\begin{array}{r}\text { Mean } \\
\left(\mathrm{W} \mathrm{m}^{-2}\right)\end{array}$ & $\begin{array}{r}\text { Bias } \\
\left(\mathrm{W} \mathrm{m}^{-2}\right)\end{array}$ & $\begin{array}{r}\text { RMSE } \\
\left(\mathrm{W} \mathrm{m}^{-2}\right)\end{array}$ & $\begin{array}{r}\text { rBias } \\
(\%)\end{array}$ & $\begin{array}{r}\text { rRMSE } \\
(\%)\end{array}$ & $R^{2}$ \\
\hline Barrow & 4293 & 20.0 & -0.2 & 1.4 & -1.1 & 6.8 & 0.98 \\
Sodankylä & 2590 & 20.8 & -0.5 & 1.9 & -2.5 & 9.0 & 0.98 \\
Jokioinen & 1140 & 22.1 & -0.5 & 1.6 & -2.1 & 7.5 & 0.98 \\
Palmer & 1736 & 24.9 & -0.8 & 1.2 & -3.1 & 4.9 & 0.99 \\
McMurdo & 10175 & 20.3 & -0.3 & 1.1 & -1.6 & 5.6 & 0.99 \\
\hline
\end{tabular}



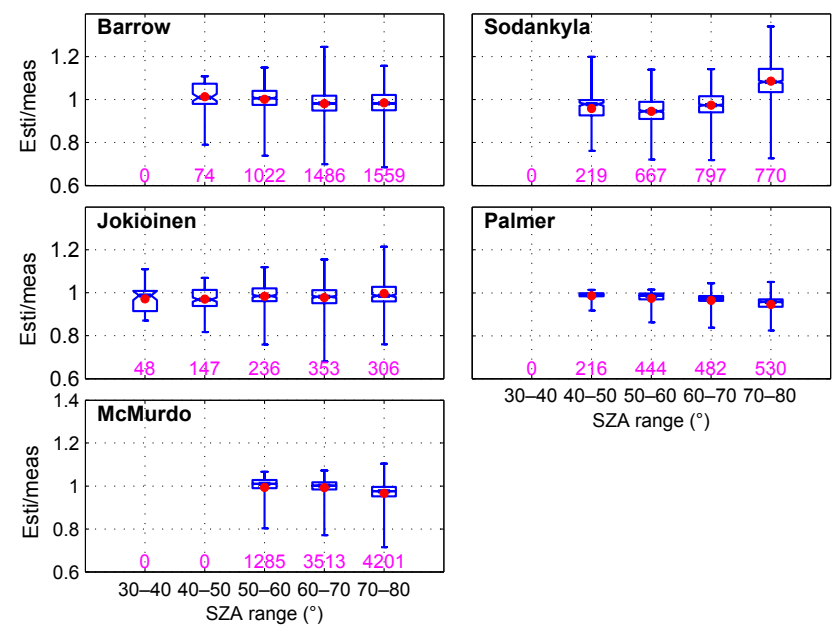

30-40 40-50 50-60 60-70 70-80 SZA range $\left(^{\circ}\right)$
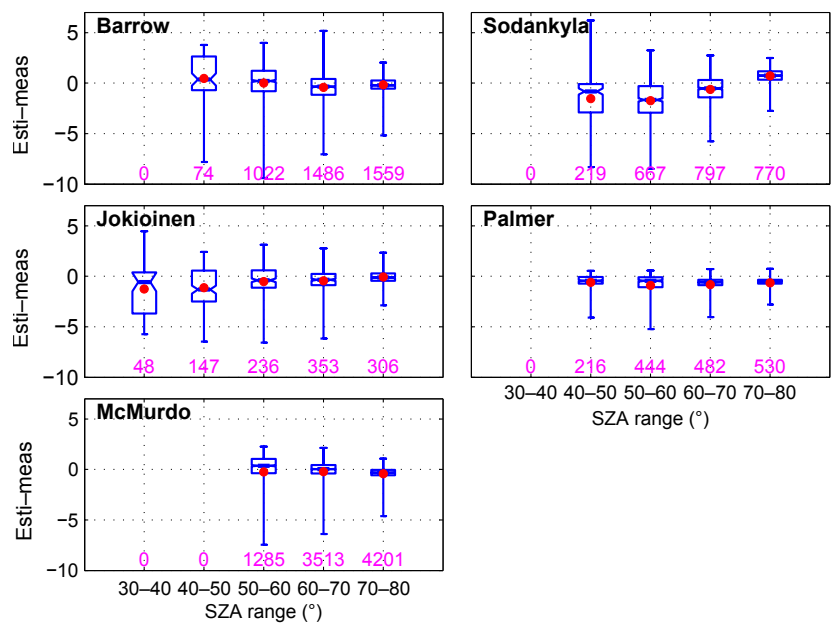

SZA range $\left({ }^{\circ}\right)$

Figure 3. Dependence of ratio (top) of the estimated (esti) to the measured (meas) UV-A irradiances for each station and the difference between the estimated and measured (bottom) UV-A irradiances for each station as a function of SZA range. The red dots indicates the mean; the limits of the boxes are the first, second (median) and third quartiles. The lower whisker is the minimum and the upper one is the maximum. The pink number is the number of data in a single SZA range.

The RMSE is low with a value of $1.9 \mathrm{~W} \mathrm{~m}^{-2}(9 \%)$. As for Jokioinen (Fig. 2c), all points are well located along the identity line. $R^{2}$ is 0.98 . The bias is low with a value of $-0.5 \mathrm{~W} \mathrm{~m}^{-2}$, i.e., $-2 \%$ of the mean value of the measurements, $22.1 \mathrm{~W} \mathrm{~m}^{-2}$, as well as the RMSE with a value of $1.6 \mathrm{~W} \mathrm{~m}^{-2}(8 \%)$.

Results for Palmer are shown in Fig. 2d. One may note that the points are well aligned with low scatter along a straight line whose slope is 0.99 with a slight underestimation by the method. The bias is $-0.8 \mathrm{~W} \mathrm{~m}^{-2}$ ( $-3 \%$ of the mean value of $\left.24.9 \mathrm{~W} \mathrm{~m}^{-2}\right)$. The RMSE is $1.2 \mathrm{~W} \mathrm{~m}^{-2}(5 \%) . R^{2}$ is greater than 0.99. Cloud-free conditions occur mostly between Au- gust and April. The shortwave albedo slightly increases from 0.28 to 0.32 between August and March and then decreases until April up to 0.20. These values are small and close to those of a ground free of snow or ice. The effective UV albedo is usually greater than 0.3 with peaks up to 0.8 . This difference between the shortwave and effective UV albedo may explain the slight underestimation indicated in Fig. 5.

Results for McMurdo are shown in Fig. 2e. Cloud-free conditions occur mostly between April and September. The points are aligned along the identity line. $R^{2}$ is 0.99 . The bias is low with a value of $-0.3 \mathrm{~W} \mathrm{~m}^{-2}(-1 \%$ of the mean value of $21.0 \mathrm{~W} \mathrm{~m}^{-2}$ ), as well as the RMSE with a value of $1.2 \mathrm{~W} \mathrm{~m}^{-2}(6 \%)$. The shortwave albedo may reach 0.8 and there is no clear discrepancy between the shortwave and effective UV albedo. Nevertheless, the authors believe that the outliers may be explained by a difference in albedo.

The dependence of errors as a function of SZA was investigated. Figure 3 exhibits the ratio (top) and difference (bottom) as function of $\theta_{\mathrm{s}}$ for each station for UV-A irradiances. For the ratio, the limits of the boxes are close from one quartile to another, meaning a very limited spread of the ratio. The deviations between maximum and minimum are approximately small. The median is similar to the mean. Regardless of the number of data (in pink color), the deviations are very close to 1 for all SZA ranges and stations except Sodankylä at high $\theta_{\mathrm{s}}$. As for the ratio, the similar observations are also seen in terms of the differences at the bottom of Fig. 3. The difference is very close to 0 for all the SZA ranges. The absolute value of the mean difference shows a tendency to decrease as $\theta_{\mathrm{s}}$ increases, with the maximum being reached for low $\theta_{\mathrm{s}}$.

The dependence of errors as a function of TOC and albedo was also investigated (not shown). The results have revealed that there is no clear dependence of errors as a function of TOC or albedo for all stations. In addition, the absolute values of the bias (not shown) show a tendency to decrease as $\theta_{\mathrm{s}}$ increases, with the maximum being reached for low $\theta_{\mathrm{s}}$, except McMurdo. In the opposite manner, the absolute values of the relative bias show a tendency to increase with $\theta_{\mathrm{s}}$. This could be related to the fact that low $\theta_{\mathrm{s}}$ are reached in summer, with greater values in UV irradiance and lower values in effective UV albedo.

\subsection{Performance of the method for UV-B irradiance}

The UV-B band is the spectral region of UV irradiance where the ozone absorption is very strong. Figure 4 exhibits the scatter density plots between measurements of UV-B and estimates for each station. Table 6 reports the statistical indicators for UV-B. $R^{2}$ is greater than 0.97 for all stations, meaning that variability in UV-B is very well reproduced by the estimates. In general, the method overestimates the UVB irradiances. Visually, one observes that the method clearly overestimates when the irradiance is low. For the wavelength less than $320 \mathrm{~nm}$, in Fig. 1, the proposed method seems to 
Table 6. Statistical indicators of the performances of the method for UV-B irradiance. $N$ is the number of data points.

\begin{tabular}{lrrrrrrr}
\hline Station & $N$ & $\begin{array}{r}\text { Mean } \\
\left(\mathrm{W} \mathrm{m}^{-2}\right)\end{array}$ & $\begin{array}{r}\text { Bias } \\
\left(\mathrm{W} \mathrm{m}^{-2}\right)\end{array}$ & $\begin{array}{r}\text { RMSE } \\
\left(\mathrm{W} \mathrm{m}^{-2}\right)\end{array}$ & $\begin{array}{r}\text { rBias } \\
(\%)\end{array}$ & $\begin{array}{r}\text { rRMSE } \\
(\%)\end{array}$ & $R^{2}$ \\
\hline Barrow & 4293 & 0.57 & 0.08 & 0.10 & 13.41 & 18.01 & 0.97 \\
Sodankylä & 2590 & 0.65 & 0.05 & 0.09 & 7.74 & 13.91 & 0.98 \\
Jokioinen & 1140 & 0.75 & 0.05 & 0.10 & 6.70 & 13.74 & 0.98 \\
Palmer & 1736 & 1.03 & -0.04 & 0.12 & -4.24 & 11.67 & 0.99 \\
McMurdo & 10175 & 0.72 & 0.04 & 0.09 & 4.86 & 12.32 & 0.98 \\
\hline
\end{tabular}
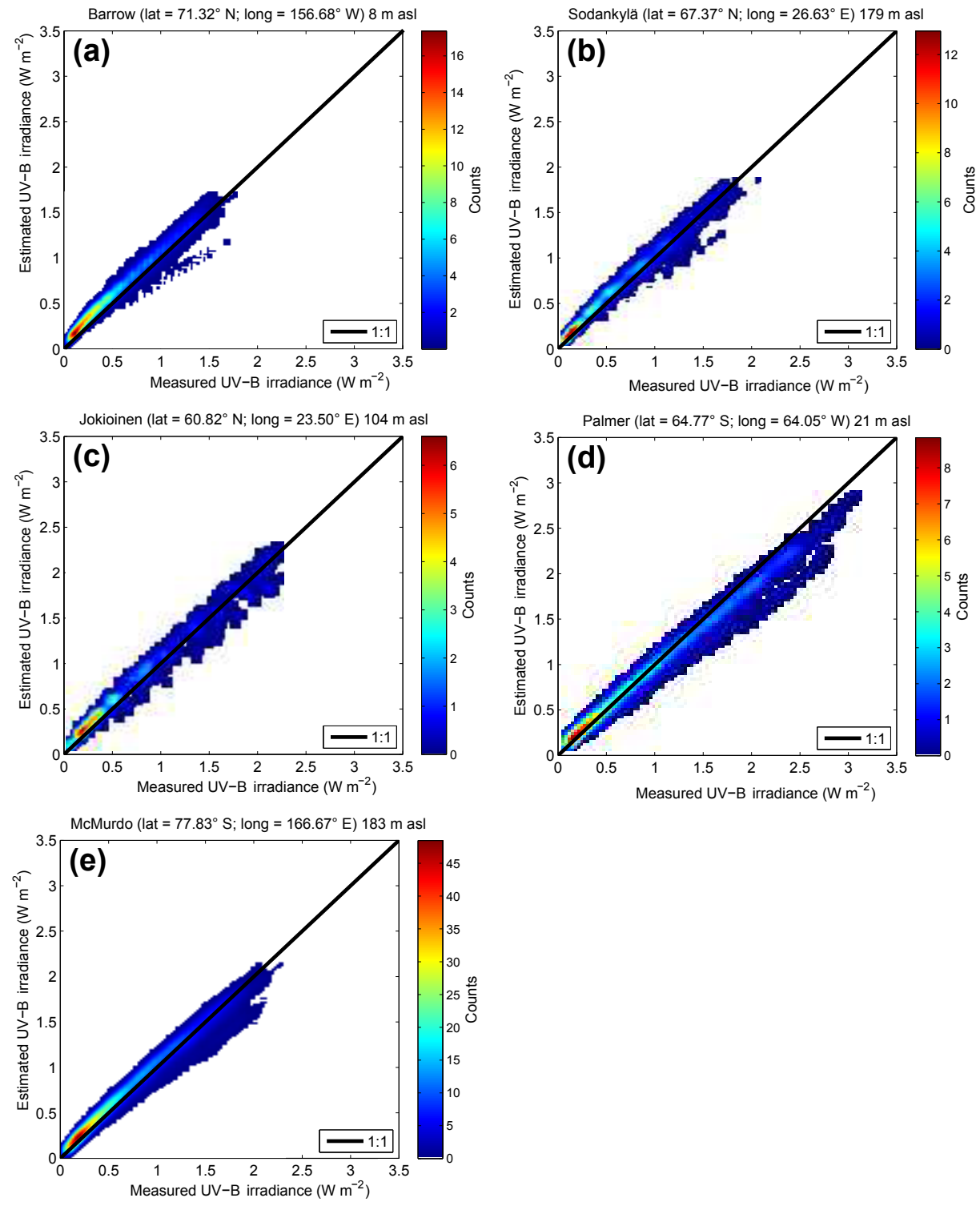

Figure 4. Same as Fig. 2, but for UV-B irradiance. 

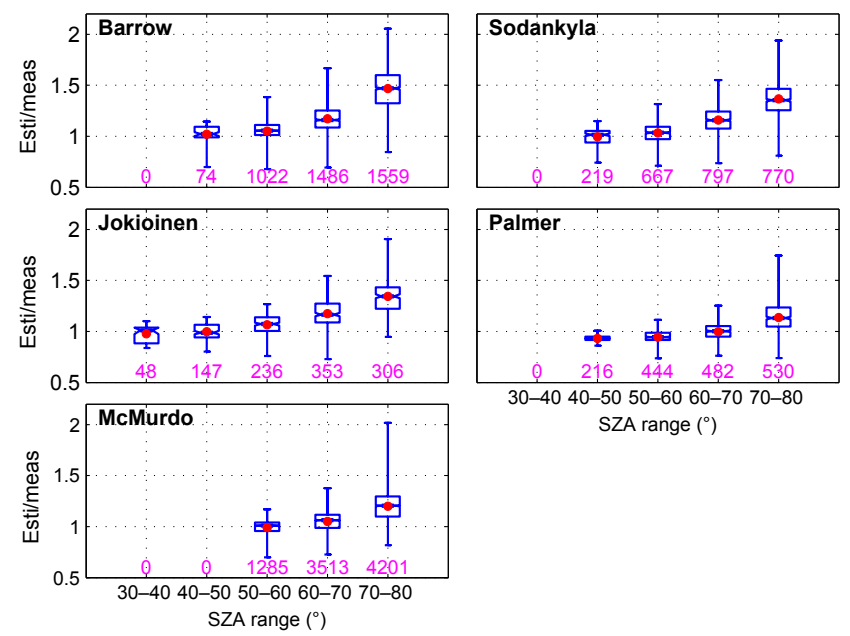

30-40 40-50 50-60 60-70 70-80 SZA range $\left({ }^{\circ}\right)$
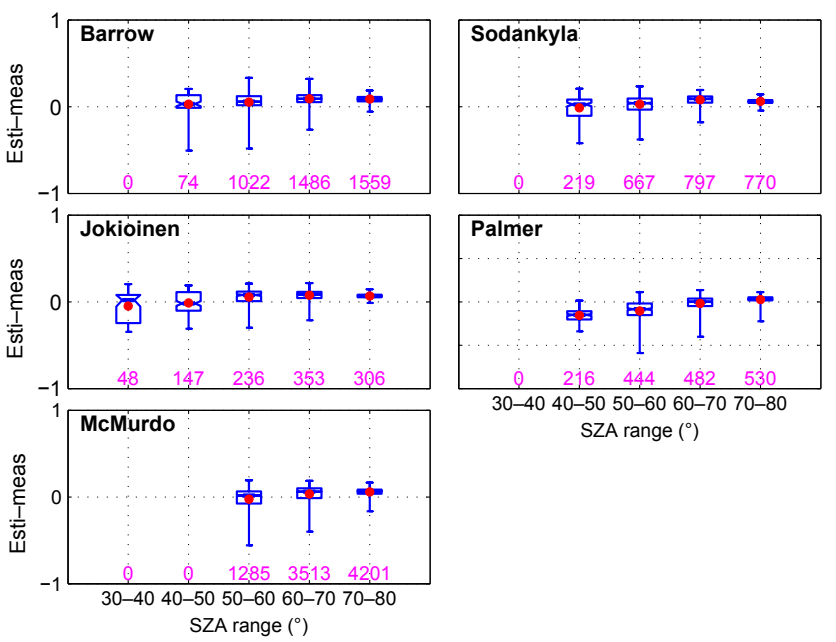

SZA range $\left({ }^{\circ}\right)$

Figure 5. Same as Fig. 3, but for UV-B irradiance.

mostly overestimate when compared to the detailed spectral calculations serving as reference. This observation induces a systematic overestimation at low irradiance from the method. This mainly explains this previous observation. The absolute value of the bias is less than $0.1 \mathrm{~W} \mathrm{~m}^{-2}$. The relative bias ranges between $-4 \%$ (Palmer) and $13 \%$ (Barrow). The rRMSE ranges between $12 \%$ and $18 \%$.

Figure 5 shows the change in ratio and relative difference as a function of $\theta_{\mathrm{s}}$. For both ratio and differences, the spread of limits of the boxes is more or less visible. Nevertheless, the median and the mean are close. The deviations show a tendency to increase with $\theta_{\mathrm{s}}$ for all stations, probably meaning that a systematic bias from the method is more visible at high $\theta_{\mathrm{S}}$ as mentioned above. These results explained the main sources of errors for the dependence of errors as a function of TOC and albedo.

In addition, one notices a tendency of the bias to reach a maximum between 65 and $75^{\circ}$ (not shown); this appears in the form of a plateau around $65^{\circ}$ for the RMSE which decreases as $\theta_{\mathrm{s}}$ increases, i.e., as the irradiance decreases. The relative bias increases with $\theta_{\mathrm{s}}$ as well as the rRMSE. Both are closer in the high $\theta_{\mathrm{s}}$ than in the small $\theta_{\mathrm{s}}$.

\section{Discussion and conclusion}

The comparison has demonstrated a reasonable agreement between the ground-based measurements of UV-A and UV-B and the estimates by the proposed method with CAMS products as inputs. The variability in UV fluxes is well reproduced by the method. A good level of accuracy is reached that is close to the uncertainty of the measurements themselves. The computations of the fluxes in the KBs can be performed quite fast with the use of precomputed look up tables as shown by the example of the McClear model. This model is an accurate approximation of libRadtran but $10^{5}$ times faster. The proposed method extends the results of the McClear model to the UV range and can be used in future operational tools that are both accurate and fast.

Further improvements are needed. A major improvement would be the extension to all sky conditions. In this aspect, one may build on the work of Oumbe et al. (2014a, b), who demonstrated that, in the case of an infinite planeparallel single- and double-layered cloud, the solar irradiance at ground level computed by a radiative transfer model can be approximated by the product of the irradiance under clear atmosphere and a modification factor that depends on cloud properties and ground albedo only as changes in clearatmosphere properties have a negligible effect on this factor. Such an approximation has been exploited previously with limited justification by several authors in studies on broadband irradiance (Huang et al., 2011), UV or photosynthetically active radiation (see e.g., Calbo et al., 2005; den Outer et al., 2010; Krotkov et al., 2001).

Another improvement consists in the modeling of the surface albedo in the UV range. Maps of BRDF parameters in the UV range must be created with a satisfactory spatial resolution of $0.05^{\circ}$ or better. The MODIS BRDF parameters may be a starting point as they are available at several wavelengths. It could be possible to apply the technique used by Blanc et al. (2014) to create BRDF maps for each wavelength and for each calendar month with no missing values. The smallest wavelength in the MODIS BRDF is approximately $470 \mathrm{~nm}$, i.e., outside the UV range, and extrapolation towards small wavelengths will be necessary.

Data availability. UV data from Barrow, Palmer station and McMurdo station were provided by the NSF UV Monitoring Network operated by Biospherical Instruments Inc. and funded by the US National Science Foundation's Office of Polar Programs. Version 2 data used here are available from http://uv.biospherical.com/ Version2/Version2.asp

FMI's spectral Brewer UV measurements are available through the European UV Database: http://uv.fmi.fi/uvdb/ 
Products from CAMS can be downloaded from the following website: http://atmosphere.copernicus.eu/

The BRDF maps by Blanc et al. (2014) may be downloaded from the following website: http://www.oie.mines-paristech. fr/Valorisation/Outils/AlbedoSol/

Competing interests. The authors declare that they have no conflict of interest.

Acknowledgements. William Wandji Nyamsi was partly supported by Fondation Mines ParisTech. We thank Harry Slaper for performing studies of uncertainties in SHICrivm.

Edited by: Alexander Kokhanovsky

Reviewed by: three anonymous referees

\section{References}

Aculinin, A., Brogniez, C., Bengulescu, M., Gillotay, D., Auriol, F., and Wald, L.: Assessment of several empirical relationships for deriving daily means of UV-A irradiance from Meteosatbased estimates of the total irradiance, Remote Sensing, 8, 537, https://doi.org/10.3390/rs8070537, 2016.

Arola, A., Kaurola, J., Koskinen, L., Tanskanen, A., Tikkanen, T., Taalas, P., and Fioletov, V.: A new approach to estimating the albedo for snow-covered surfaces in the satellite UV method, J. Geophys. Res.-Atmos., 108, https://doi.org/10.1029/2003JD003492, 2003.

Bernhard, G., Booth, C. R., and Ehramjian, J. C.: UV climatology at Palmer Station, Antarctica, based on version 2 NSF network data, Proc. SPIE, 5886, 588607-01, https://doi.org/10.1117/12.614172, 2005.

Bernhard, G., Booth, C. R., Ehramjian, J. C., and Nichol, S. E.: UV climatology at McMurdo station, Antarctica, based on version 2 data of the National Science Foundation's ultraviolet radiation monitoring network, J. Geophys. Res.-Atmos., 111, 2006.

Bernhard, G., Booth, C. R., Ehramjian, J. C., Stone, R. and Dutton, E. G.: Ultraviolet and visible radiation at Barrow, Alaska: Climatology and influencing factors on the basis of version 2 National Science Foundation network data, J. Geophys. Res.-Atmos., 112, D09101, https://doi.org/10.1029/2006JD007865, 2007.

Bernhard, G., Booth, C. R., and Ehramjian, J. C.: Comparison of UV irradiance measurements at Summit, Greenland; Barrow, Alaska; and South Pole, Antarctica, Atmos. Chem. Phys., 8, 4799-4810, https://doi.org/10.5194/acp-8-4799-2008, 2008.

Blanc, P. and Wald, L.: The SG2 algorithm for a fast and accurate computation of the position of the Sun, Sol. Energy, 86, 30723083, https://doi.org/10.1016/j.solener.2012.07.018, 2012.

Blanc, P., Gschwind, B., Lefèvre, M., and Wald, L.: The HelioClim project: Surface solar irradiance data for climate applications, Remote Sensing, 3, 343-361, https://doi.org/10.3390/rs3020343, 2011.

Blanc, P., Gschwind, B., Lefèvre, M., and Wald, L.: Twelve monthly maps of ground albedo parameters derived from MODIS data sets, in: Proceedings of IGARSS 2014, 13-18 July 2014, Quebec, Canada, USBKey, 3270-3272, available at: http://www.oie.
mines-paristech.fr/Valorisation/Outils/AlbedoSol/ (last access: 1 December 2017), 2014.

Calbó, J., Pages, D., and González, J. A.: Empirical studies of cloud effects on UV radiation: A review, Rev. Geophys., 43, RG2002, https://doi.org/10.1029/2004RG000155, 2005.

Canada, J., Pedros, G., Lopez, A., and Bosca, J. V.: Influences of the clearness index for the whole spectrum and of the relative optical air mass on UV solar irradiance for two locations in the Mediterranean area, Valencia and Cordoba, J. Geophys. Res., 105, 4759 4766, 2003.

Coste, A., Goujon, S., Boniol, M., Marquant, F., Faure, L., Doré, J.-F., Hémon, D., and Clavel, J.: Residential exposure to solar ultraviolet radiation and incidence of childhood hematological malignancies in France, Cancer Cause. Control, 26, 1339-1349, 2015.

de Gruijl, F. R., Sterenborg, H. J., Forbes, P. D., Davies, R. E., Cole, C., Kelfkens, G., van Weelden, H., Slaper, H., and van der Leun, J. C.: Wavelength dependence of skin cancer induction by ultraviolet irradiation of albino hairless mice, Cancer Res., 53, 53-60, 1993.

Delcourt, C., Cougnard-Grégoire, A., Boniol, M., Carrière, I., Doré, J.-F., Delyfer, M.-N. Rougier, M.-B., Le Goff, M., Dartigues, J.F., Barberger-Gateau, P., and Korobelnik, J. F.: Lifetime exposure to ambient ultraviolet radiation and the risk for cataract extraction and age-related macular degeneration: The Alienor study, Investig. Ophthalmol. Vis. Sci., 55, 7619-7627, 2014.

den Outer, P. N., Slaper, H., Kaurola, J., Lindfors, A., Kazantzidis, A., Bais, A. F., Feister, U., Junk, J., Janouch, M., and Josefsson, W.: Reconstructing of erythemal ultraviolet radiation levels in Europe for the past 4 decades, J. Geophys. Res.-Atmos., 115, D10102, https://doi.org/10.1029/2009JD012827, 2010.

Emde, C., Buras-Schnell, R., Kylling, A., Mayer, B., Gasteiger, J., Hamann, U., Kylling, J., Richter, B., Pause, C., Dowling, T., and Bugliaro, L.: The libRadtran software package for radiative transfer calculations (version 2.0.1), Geosci. Model Dev., 9, 1647-1672, https://doi.org/10.5194/gmd-9-1647-2016, 2016.

Fortes, C., Mastroeni, S., Bonamigo, R., Mannooranparampil, T., Marino, C., Michelozzi, P., Passarelli, F., and Boniol, M.: Can ultraviolet radiation act as a survival enhancer for cutaneous melanoma?, Eur. J. Cancer Prev., 25, 34-40, 2016.

Foyo-Moreno, I., Vida, J., and Alados-Arboledas, L.: Ground-based ultraviolet (290-385 $\mathrm{nm}$ ) and broadband solar radiation measurements in South-eastern Spain, Int. J. Climatol., 18, 1389-1400, 1998.

Gueymard, C.: The sun's total and the spectral irradiance for solar energy applications and solar radiations models, Sol. Energy, 76, 423-452, 2004.

Heikkilä, A., Sakari Mäkelä, J., Lakkala, K., Meinander, O., Kaurola, J., Koskela, T., Karhu, J. M., Karppinen, T., Kyrö, E., and de Leeuw, G.: In search of traceability: two decades of calibrated Brewer UV measurements in Sodankylä and Jokioinen, Geosci. Instrum. Method. Data Syst., 5, 531-540, https://doi.org/10.5194/gi-5-531-2016, 2016a.

Heikkilä, A., Kaurola, J., Lakkala, K., Karhu, J. M., Kyrö, E., Koskela, T., Engelsen, O., Slaper, H., and Seckmeyer, G.: European UV DataBase (EUVDB) as a repository and quality analyser for solar spectral UV irradiance monitored in Sodankylä, Geosci. Instrum. Method. Data Syst., 5, 333-345, https://doi.org/10.5194/gi-5-333-2016, 2016 b. 
Herman, J. R. and Celarier, E. A.: Earth surface reflectivity climatology at $340 \mathrm{~nm}$ to $380 \mathrm{~nm}$ from TOMS data, J. Geophys. Res., 102, 28003-28011, 1997.

Huang, G. H., Ma, M. G., Liang, S. L., Liu, S. M., and Li, X.: A LUT-based approach to estimate surface solar irradiance by combining MODIS and MTSAT data, J. Geophys. Res.-Atmos., 116, D22201, https://doi.org/10.1029/2011JD016120, 2011.

ISO Guide to the Expression of Uncertainty in Measurement: first edition, International Organization for Standardization, Geneva, Switzerland, 1995.

Juzeniene, A., Brekke, P., Dahlback, A., Andersson-Engels, S., Reichrath, J., Moan, K., Holick, M. F., Grant, W. B., and Moan, J.: Solar radiation and human health, Rep. Prog. Phys. 74, 066701, https://doi.org/10.1088/0034-4885/74/6/066701, 2011.

Kato, S., Ackerman, T., Mather, J., and Clothiaux, E.: The $k$ distribution method and correlated- $k$ approximation for shortwave radiative transfer model, J. Quant. Spectrosc. Ra., 62, 109121, 1999.

Kravietz, A., Ka, S., Wald, L., Dugravot, A., Singh-Manoux, A., Moisan, F., and Elbaz, A.: Association of UV radiation with Parkinson disease incidence: a nationwide French ecologic study, Environ. Res., 154, 50-56, https://doi.org/10.1016/j.envres.2016.12.008, 2017.

Krotkov, N. A., Herman, J. R., Bhartia, P. K., Fioletov, V., and Ah$\mathrm{mad}, \mathrm{Z}$.: Satellite estimation of spectral surface UV irradiance: 2. Effects of homogeneous clouds and snow, J. Geophys. Res.Atmos., 106, 11743-11759, 2001.

Lakkala, K., Arola, A., Heikkilä, A., Kaurola, J., Koskela, T., Kyrö, E., Lindfors, A., Meinander, O., Tanskanen, A., Gröbner, J., and Hülsen, G.: Quality assurance of the Brewer spectral UV measurements in Finland, Atmos. Chem. Phys., 8, 3369-3383, https://doi.org/10.5194/acp-8-3369-2008, 2008.

Lefèvre, M., Oumbe, A., Blanc, P., Espinar, B., Gschwind, B., Qu, Z., Wald, L., Schroedter-Homscheidt, M., Hoyer-Klick, C., Arola, A., Benedetti, A., Kaiser, J. W., and Morcrette, J.-J.: McClear: a new model estimating downwelling solar radiation at ground level in clear-sky conditions, Atmos. Meas. Tech., 6, 2403-2418, https://doi.org/10.5194/amt-6-2403-2013, 2013.

Lefèvre, M., Blanc, P., Espinar, B., Gschwind, B., Ménard, L., Ranchin, T., Wald, L., Saboret, L., Thomas, C., and Wey, E.: The HelioClim-1 database of daily solar radiation at Earth surface: an example of the benefits of GEOSS Data-CORE, IEEE J-STARS, 7, 1745-1753, https://doi.org/10.1109/JSTARS.2013.2283791, 2014.

Lindfors, A., Kaurola, J., Arola, A., Koskela, T., Lakkala, K., Josefsson, W., Olseth, J. A., and Johnsen, B.: A method for reconstruction of past UV radiation based on radiative transfer modeling: Applied to four stations in northern Europe, J. Geophys. Res., 112, D23201, https://doi.org/10.1029/2007JD008454, 2007.

Lindfors, A., Heikkilä, A., Kaurola, J., Koskela, T., and Lakkala, K.: Reconstruction of solar spectral surface UV irradiances using radiative transfer simulations, Photochem. Photobiol., 85, 12331239, 2009.

Mäkelä, J. S., Lakkala, K., Koskela, T., Karppinen, T., Karhu, J. M., Savastiouk, V., Suokanerva, H., Kaurola, J., Arola, A., Lindfors, A. V., Meinander, O., de Leeuw, G., and Heikkilä, A.: Data flow of spectral UV measurements at Sodankylä and Jokioinen, Geosci. Instrum. Method. Data Syst., 5, 193-203, https://doi.org/10.5194/gi-5-193-2016, 2016.
Mayer, B. and Kylling, A.: Technical note: The libRadtran software package for radiative transfer calculations - description and examples of use, Atmos. Chem. Phys., 5, 1855-1877, https://doi.org/10.5194/acp-5-1855-2005, 2005.

Mayer, B., Seckmeyer, G., and Kylling, A.: Systematic long-term comparison of spectral UV measurements and UVSPEC modeling results, J. Geophys. Res.-Atmos., 102, 8755-8768, 1997.

McKinlay, A. F. and Diffey, B. L.: A reference action spectrum for ultraviolet induced erythema in human skin, The CIE Journal, 6, 17-22, 1987.

Mesrine, S., Kvaskoff, M., Bah, T., Wald, L., ClavelChapelon, F., and Boutron-Ruault, M.-C.: Nevi, ambient ultraviolet radiation and thyroid cancer risk: a French prospective study, Epidemiology, 28, 694-702, https://doi.org/10.1097/EDE.0000000000000673, 2017.

Norval, M.: The effect of ultraviolet radiation on human viral infections, Photochem. Photobiol., 82, 1495-1504, 2006.

Norval, M. and Halliday, G. M.: The consequences of UV-induced immunosuppression for human health, Photochem. Photobiol. 87, 965-977, https://doi.org/10.1111/j.1751-1097.2011.00969.x, 2011.

Orton, S.-M., Wald, L., Confavreux, C., Vukusic, S., Krohn, J. P., Ramagopalan, S. V., Herrera, B. M., Sadovnick, A. D., and Ebers, G. C.: Association of UV radiation with multiple sclerosis prevalence and sex ratio in France, Neurology, 76, 425-431, https://doi.org/10.1212/WNL.0b013e31820a0a9f, 2011.

Oumbe, A., Blanc, Ph., Gschwind, B., Lefevre, M., Qu, Z., Schroedter-Homscheidt, M., and Wald, L.: Solar irradiance in clear atmosphere: study of parameterisations of change with altitude, Adv. Sci. Res., 6, 199-203, https://doi.org/10.5194/asr-6199-2011, 2011.

Oumbe, A., Qu, Z., Blanc, P., Lefèvre, M., Wald, L., and Cros, S.: Decoupling the effects of clear atmosphere and clouds to simplify calculations of the broadband solar irradiance at ground level, Geosci. Model Dev., 7, 1661-1669, https://doi.org/10.5194/gmd-7-1661-2014, 2014a.

Oumbe, A., Qu, Z., Blanc, P., Lefèvre, M., Wald, L., and Cros, S.: Corrigendum to "Decoupling the effects of clear atmosphere and clouds to simplify calculations of the broadband solar irradiance at ground level" published in Geosci. Model Dev., 7, 1661-1669, 2014, Geosci. Model Dev., 7, 2409-2409, https://doi.org/10.5194/gmd-7-2409-2014, 2014b.

Schaaf, C. B., Gao, F., Strahler, A. H., Lucht, W., Li, X. W., Tsang, T., Strugnell, N. C., Zhang, X. Y., Jin, Y. F., Muller, J. P., Lewis, P., Barnsley, M., Hobson, P., Disney, M., Roberts, G., Dunderdale, M., Doll, C., d'Entremont, R. P., Hu, B. X., Liang, S. L., Privette, J. L., and Roy, D.: First operational BRDF, albedo nadir reflectance products from MODIS, Remote Sens. Environ., 83, 135-148, https://doi.org/10.1016/S0034-4257(02)00091-3, 2002.

Setlow, R. B., Grist, E., Thompson, K. and Woodhead, A. D.: Wavelengths effective in induction of malignant melanoma, P. Natl Acad. Sci. USA, 90, 6666-6670, 1993.

Slaper, H. and Koskela, T.: Methodology of intercomparing spectral sky measurements, correcting for wavelength shifts, slit function differences and defining a spectral reference, in: The Nordic intercomparison of ultraviolet and total ozone instruments at Izana, October 1996, Izana, Meteorological Publications 36, edited by: 
Kjeldstad, B., Johnson, B., and Koskela, T., Finnish Meteorological Institute, 89 pp., 1997.

Slaper, H., Reinen, H., Blumthaler, M., Huber, M., and Kuik, F.: Comparing ground-level spectrally resolved solar UV measurements using various instruments: A technique resolving effects of wavelength shift and slit width, Geophys. Res. Lett., 22, 27212724, 1995.

Stamnes, K., Tsay, S.-C., Wiscombe, W., and Laszlo, I.: DISORT, a general purpose Fortran program for discrete ordinate method radiative transfer in scattering and emitting layered media: Documentation of methodology, Tech. Rep., Dept. of Physics and Engineering Physics, Stevens Institute of Technology, Hoboken, NJ07030, USA, 2000.

Varotsos, C. A., Melnikova, I. N., Cracknell, A. P., Tzanis, C., and Vasilyev, A. V.: New spectral functions of the near-ground albedo derived from aircraft diffraction spectrometer observations, Atmos. Chem. Phys., 14, 6953-6965, https://doi.org/10.5194/acp14-6953-2014, 2014.
Wandji Nyamsi, W., Espinar, B., Blanc, P., and Wald, L.: How close to detailed spectral calculations is the $k$-distribution method and correlated- $k$ approximation of Kato et al. (1999) in each spectral interval?, Meteorol. Z., 23, 547-556, https://doi.org/10.1127/metz/2014/0607, 2014.

Wandji Nyamsi, W., Espinar, B., Blanc, P., and Wald, L.: Estimating the photosynthetically active radiation under clear skies by means of a new approach, Adv. Sci. Res., 12, 5-10, https://doi.org/10.5194/asr-12-5-2015, 2015a.

Wandji Nyamsi, W., Arola, A., Blanc, P., Lindfors, A. V., Cesnulyte, V., Pitkänen, M. R. A., and Wald, L.: Technical Note: A novel parameterization of the transmissivity due to ozone absorption in the $k$-distribution method and correlated- $k$ approximation of Kato et al. (1999) over the UV band, Atmos. Chem. Phys., 15, 7449-7456, https://doi.org/10.5194/acp-15-7449-2015, 2015b.

WMO: Guide to Meteorological Instruments and Methods of Observation, WMO-No. 8, 2008 Edn., updated in 2010, World Meteorological Organization, Geneva, Switzerland, 2008. 